\title{
Psychology of Light: How Light Influences the Health and Psyche
}

\author{
Rosella Tomassoni, Giuseppe Galetta, Eugenia Treglia \\ Department of Human, Social and Health Sciences, University of Cassino and Southern Latio, Cassino, Italy \\ Email: tomassoni@unicas.it, giuseppe.galetta@unicas.it, e.treglia@unicas.it
}

Received 30 June 2015; accepted 2 August 2015; published 5 August 2015

Copyright (C) 2015 by authors and Scientific Research Publishing Inc.

This work is licensed under the Creative Commons Attribution International License (CC BY).

http://creativecommons.org/licenses/by/4.0/

(c) (i) Open Access

\begin{abstract}
Light is the stimulus that influences most the human perception, but also the psychophysical wellbeing of the individual in everyday life. This paper analyzes the light from a psychological point of view, investigating the relationships between light-based emotions and behaviours, and the psychophysical responses to lit environment by the perceivers in different experiential contexts. Light becomes, therefore, "Cognitive Map" and "Emotional Driver", but also a "Gestaltic Device" for the perceiver, in order to understand and interpret the external reality. Even the dark and lighting deprivation were considered, not only as environmental conditioning on the mood (Fusco, 2005a), but also through the psychological analysis of specific light manipulation techniques, such as "Sendep" and "Ganzfeld Effect". Finally, some guidelines were shown to improve health and wellness of the individual exposed to the light in a given environment (healthy lighting), getting to define an "Ecological" approach to light and lighting perception in human life, that would also involve some light-based techniques, such as Light Design and Light Art.
\end{abstract}

\section{Keywords}

Psychology of Light, Light Perception, Light Design, Ligh Art, Lighting Psychology

\section{Introduction}

From a psychological point of view, talking about the light is like plunging into the depths of the psyche, but also dealing with the limits and possibilities of the perceptive skills, natural equipment of the human psychophysical apparatus, influencing our health and wellness throughout the life.

Light was analyzed not only by a perceptive point of view, but also as a driver of cognitive, emotional and behavioural responses by the perceiver in different experiential contexts of everyday life. It showed that light is a Cognitive Map able to guide and direct the individual in the exploration and discovery of the surrounding en- 
vironment, providing the interpretative keys of an increasingly complex reality.

Even the dark (i.e. the opposite of light) was analyzed, describing the effects of specific sensory deprivation or light manipulation techniques on the neuro-perceptual sphere of the perceiver, that may be used for breaking the individual's will, by changing the reality perception (such as in a war scenario), but also to increase the aesthetic enjoyment of the viewer, as in the case of Light Art installations.

From our perspective, the study of psychological effects of light and lighting on the individual should lead to an overall "ecological" approach to light perception.

\section{Light as a Cognitive Map and Emotional Driver}

Beyond the classical behavioural model of stimulus-response, the neuro-perceptive reaction mechanisms, and the environmental adaptation by the perceiver, light may stimulate our perceptual apparatus through type and range of exposure to a lighting source and its colours, inducing specific emotional states or behaviour in the human: this specific type of stimulus is able to excite, move, impress, communicate, heal and generate wellness, creating a sense of harmony and syntony with the surrounding environment, like a home interior, a store corner, an office space, or an exhibition wing of a museum (Birren, 1969a, 1969b; Flynn et al., 1973).

The strategic layout and modulation of lighting by light designers may influence the perceiver's mood, creating a sense of calm and rest in a sacred environment (as a temple or a church), or add mystery and suspense to a theatre performance on the stage, driving the eye's direction and the meaning attribution inside a specific space-time context (Flynn, 1973): light is therefore an environmental "cognitive map" and a psychophysical driver of human perception. The induction of specific cognitive and emotional responses by an individual exposed to a light setting inside a domestic, architectural, urban, commercial, working, or exhibition space (e.g. a museum or art gallery), but also into the natural environment (Kaplan \& Kaplan, 1989), largely determined by human neuronal asset and psychophysical equipment, is one of the most evident effects of the light, although sometimes light designers, because of their focus on the functional or aesthetic values related to their lighting projects, are not fully aware.

Within a home or working space, light is able to induce-according to its intensity, saturation and modulation — specific emotional states, but also activate specific cognitive skills inside the perceiver (Flynn, 1977): dynamism, relaxation, privacy, visual clarity, excitation, productivity, efficiency, but also stress, sleepiness, sadness, agitation, restlessness, anxiety. The individual response by a subject exposed to the light is variable inside the range between the extremes of a light source, that can be bright/dim, uniform/non-uniform, central/perimeter, warm/cool: in short, it is possible to induce a change of the psychophysiological responses by the perceiver through the alteration/modulation of the nature and typology of light stimuli within a continuum of variations, allowing also the measurement of subjective impressions in lighting conditions (Flynn et al., 1979; Boyce, 2003). Furthermore, the synesthetic possibilities of human perception, and the range of emotional responses by each individual exposed to the light, grow if - besides the impact generated by a light source—we also add a sound stream, such as a piece of music. Moreover, colored light may evoke a tactile sensation in the perceiver (according to the range of chromatic hue), manifesting itself in the form of perceived temperature, implementing modalities of synesthetic perception in the human: in this way, the individual may be able to "feel" the light (Berry, 1961).

\section{Light as a Gestaltic Device}

On the basis of a psycho-cognitive approach, the environmental cognition, that is the basic need of human being to give meaning to the surrounding environment, through the activation of mental processes about matching and assimilation of stimuli coming from the external reality towards familiar and already known patterns that fall within the subject's experiential sphere, allows to recognize the light as one of the primary factors of the process of mental reconstruction, interpretative decoding, symbolic decryption and semantic reappropriation of the environmental space by the perceiver: light is, therefore, a device (natural or artificial) that supports the brainworkofreconstruction and classification of reality by the viewer, setting the syntax rules of visual perception (Galetta, 2014). This process of Gestaltic reconstruction about the surrounding environment through the light, which involves simultaneously both the sensorineural sphere and the individual unconscious, is intended to bridge the cognitive gap relating to a reality unknown by the subject, giving humans the correct interpretative keys about the outer environmental space and the necessary answers to their security basic need, enabling them to overcome 
the instinctive and primitive defense mechanisms against the unknown, that may determine fear (instinct to escape) or aggressiveness (instinct to attack): so, light helps to give meaning to the environment and drive the process of interpretation of reality (but also adaptation to that), performed by a subject in a state of cognitive uncertainty in order to controlling the external environment. But, at the same time, human being is also attracted by a sense of mystery and complexity, that arises from the discovery of a new and unknown environment, being inclined to prefer "unconventional" solutions, in which light, with its many shades and gradations, leads the individual through the process of exploration towards the unknown: paradoxically, light seems to hide, rather than reveal the mystery, but just for this it attracts, involves, stimulates and fascinates us so much. While coherence reassures, complexity fascinates us; but either way, light always drives our visual apparatus through the semantic path of environmental information decoding, whether that comes from a domestic or working environment, an architectural or urban space, a store corner, a building interior, or an exhibition space of a museum or art gallery: light, and its perception by human, shapes the world (Lam, 1992).

According to the model of mental processing provided by each individual, based in part on his/her own neuro-perceptual structures, partly on the subjective personality and unconscious drives, light stimuli (i.e. sensory input) will be able to induce specific emotions, behaviours and mood (Fusco, 2005b, 2012; Fusco et al., 2011; Tomassoni, 2014), as well as influence bodily and mental health, but also the level of aesthetic appreciation by the perceiver towards a given environment, especially if the same viewer (and not the light designer) controls the light source, that becomes a source of aesthetic pleasure or environmental enjoyment by the subject. Due to the capacity of light-whether natural or artificial, colored or fluorescent, evanescent or material- to induce specific perceptive alterations within the sensory sphere of the human, the holistic, all-encompassing, and immersive dimension of individual involvement is, therefore, the key to the effectiveness of any lit environment. Light source, the energy that emanates from it, and the light-generated biopsychic effects, just become the focus of all perceptual mechanisms and interpretative processes implemented by each perceiver: light has not only the role to make visible an object for a viewer, but also to contextualize it within the environmental space. For example, the location of an object within the environment, according to the angle of incidence of one or more light sources, as well as the capacity of the object in absorbing and reflecting the light (luminous radiance or reflectance), are capable of driving human perception and emotions, as well as influencing the bodily and mental wellness (Collins, 1993).

As already noted by Arnheim (1954), by a perceptual point of view, human eye is not able to distinguish between the reflection power of an object and its real light emanation: eyes receives only the final result by a gestaltic impression, that is the intensity of light perceived within the visual field by the human: this is the reason why a light-reflecting object seems to emanate a light of its own, as if this was an property inherent the object in itself. Therefore, what influences the psychophysical viewer's apparatus is the overall effect of the environment exposed to a light source, together with the object positioning within a space context: Light Design takes advantage of that cumulative effect, related to the sum of all the above factors (object + light + environment) to induce specific emotions, behaviours and psychophysical feedbacks by the perceiver, influencing his/her health and wellness. The so-called Light Art, for example, uses various types light sources (such as Neon, LED, fluorescent lighting, and so on), namely objects emanating a specific luminous energy inherent to the same lighting devices, but such energy (and its chromatic spectrum) is mixed to the items present on the set, appropriately positioned in the environmental space to be able to absorb and reflect light energy in a precise exhibition strategy, in order to produce an overall perceptual effect in the perceiver, exciting different emotions and behaviours during the individual experience of aesthetic appreciation. In the case of realistic painting, light perceived within the depicted scene is not a light energy inherent to the canvas in itself, but an analogical representation of the light handed back by the artist through an artful use of colours, that are able to simulate light refracted by represented objects and the surrounding environment, as they reflect the light of the exhibition space (or environment) in which the artwork is positioned: house, public space, museum, art gallery, shop corner, factory, city and urban space.

\section{Light vs. Dark: Sendep and Ganzfeld Effect}

Even the dark, namely absence of light, contributes to organize and set out the surrounding environment, marking emptiness and fullness, presence and absence, given that it is the right light to make visible an object. At the same time, overlaps and intersections generated by different light intensities, are able to create shadows and depth, modulating feelings and emotions in the perceiver, who can read an object by different dark shades. At the end, all the items will converge in a well-organized project, in a visual intelligible (and gestaltic) order, in 
which light scans reading, perception and interpretation times by the perceiver. Moreover, it must consider the influence of light on the human being's biorhythms: in fact, human life is marked by the alternation of night/day, dark/light, sleep/wake and work/rest rhythms (or circadian rhythms). According to light intensity, refractive index and wavelength of the electromagnetic radiation emitted by a light source, light determines the colour perception of the objects inside a lit environment, influencing the mood and behaviour of people exposed (Veitch \& Newsham, 1998; Boyce et al., 2000).

The "Sendep" (i.e. sensory deprivation) or perceptual isolation, especially about light, has negative effects on the human being from a neuropsychiatric perspective: in fact, it has been widely used in the military field as a torture method, (such as the brainwashing), on war prisoners, as happened during Korean and Vietnam wars (Solomon et al., 1961). A related phenomenon is the so-called Ganzfeld Effect (or perceptual deprivation), that occurs when a constant and uniform light stimulus is used, instead of remove it: this leads to effects similar to sensory deprivation: for instance, by submitting an individual to a uniform lighting (or flashes of light) for a long time (Wackermann, Pütz, \& Allefeld, 2008). It is no coincidence that the American artist James Turrell, in the artwork series entitled "Ganzfeld", uses the properties of the fluorescent light to reproduce a feeling of estrangement and absence of depth field. The "Ganzfelds" are defined by Turrell as sensing spaces, namely homogeneous perceptive spaces and visual fields that provide the viewer the disorienting experience of "fullness of emptiness" or horizon's absence, enhancing the perception of real space and permitting the views of so-called skyspaces. Through his art research about the control-based use of light, James Turrell (together with his colleague Robert Irwin, and the perception psychologist Edward Wortz) explores the human perception processes in controlled environments, in a state of alteration of perception, performing experiments about the total perceptual fields (Ganzfeld) and sensory deprivation, as a part of Art and Technology Program, established by the Los Angeles County Museum of Art (in collaboration with scientists and engineers at Lockheed Aircraft, IBM and Garrett Aerospace Corporation).

\section{Lighting and Environment: Towards an "Ecological" Approach to Light Perception}

Research about the relationships between lighting levels and colours by one side, bio-physiological and neuropsychological phenomena by the other, have shown that light influences biochemical and hormonal processes, body temperature, mood, psychological well-being and electrical brain activity, influencing the neurotransmitters (Mahnke \& Mahnke, 1987): that is the reason why in the waiting rooms of public spaces (surgeries, hospitals, churches, airports, and so on) low lighting is used, accompanied by warm colours or pastel shades, in order to induce relaxation and evoke a sense of protection and hospitality (for example, light green or blue); while, in a production or competitive environment (such as the working space of an office, or a boxing or fighting ring), marked by the dynamism of production rates, high lighting accompanied by colder chromatic temperatures is able to stimulate a greater work efficiency and productivity, but also aggressiveness and competition (Tiller, 1990; Badia et al., 1991; Ginthner, 2002).

A great contribution to research about the Psychology of Light (or Lighting Psychology) was given by the eyetracking studies, namely the engineering research on the eye movements involved in vision and decoding of visual stimuli coming from the environment, which help to organize the overall perception of reality by the perceivers at various complexity levels. These studies are also contributing to the improvement of Cybernetic Systems, Artificial Intelligence, Virtual Reality and Video Games, where light perception is simulated in a similar way to that experienced in the reality by humans. In the perspective of a computational approach to aesthetics, light may be considered as the inferential engine of the aesthetic quality of an object exposed to a light source: in fact, the functional specialization of cerebral cortex has showed that the bioelectric signals transmitted to the brain by the photoreceptors, namely neurons specialized in scanning the light photons, determine the aesthetic quality of the reality perceived by humans, demonstrating the correlation between perceptual processes and visual brain (Zeki, 1999, 2008). Light Art and Light Design are creating the perfect fusion of scientific technology, art research and aesthetic perception: this is obvious if we consider the flexibility and versatility of Neon light, that allows to create, through the deep connection between space and light, and the perceptual mechanisms of the perceiver, new and unexpected aesthetic paths (Sabra, 1981).

The environmental experience by human is intimately connected with the light space, given that the space itself (in a visual sense) is a space-light, and viewers perceive spatial relationships only when light is intercepted and reflected by an object settled in a space-light context (Kepes, 1944): with the space neonization, a new form 
of artistic expression was born, as just demonstrated with famous artworks by James Turrell, Dan Flavin, and the artists of the Californian art movement of Light and Space (Butterfield, 1996). The aesthetic perception by the viewer, led by psychobiological mechanisms specialized in the course of evolution (Martindale, Locher, \& Petrov, 2007), has faced for the first time an "artificial vision" of the environmental space, that-just through the light-has become modified spatial perception, according to a precise aesthetic strategy planned by light designers (Flynn, 1988; Kaplan et al., 1998). In the Light Art artworks, as well as Light Design in general, light and lighting take up the function to illuminate the environmental (which is perceptual and experiential space), highlighting and marking objects, revealing spatial or symbolic paths, focus or divert the viewer's attention in front of a specific artwork's detail, letting out the symbolic strategy and meaning trajectories planned by the artist or light designer. In fact, through research performed by using light sources of different spectrum (from natural to artificial light), it was established a significant correlation between lighting levels and light colours, psychophysiological reactions and emotional responses by the perceivers: generally, a higher intensity of light stimulation corresponds to a higher level of concentration/attention, associated with a greater emotional response by the subject. For example, the exposure to a flashing or pulsating light (rather than a steady light) induces faster emotional responses by the perceiver: in fact, flashing light is associated with the danger, activating an innate state of alert in the human, enabling him/her to react quickly and in a most extreme way, influencing judgment abilities, problem solving and decision making skills. Through the lighting modulation (and its colour spectrum), it is possible to stimulate different emotions in human being, such as physical attraction or aggressiveness: the activation of specific neurotransmitters and the production, at biochemical level, of specific hormones in the presence of determined colour light source, shows the psychobiological bases of light perception by human, that may change according to the subject's sex or age (Burg, 1967), but also the supposed effectiveness of some alternative medicine techniques (such as chromotherapy) on the psychological wellbeing of the individual.

Lighting conditions, as well as the intensity and colour of the light source, influence indeed the human biological cycles and, by a chronopsychological point of view, the circadian rhythm, by increasing or decreasing the level of specific hormonal secretions (such as melatonin, namely the marker-hormone of circadian rhythms, produced by the pineal gland), that are responsible for certain neurophysiological states. Critical, in this sense, was the discovery of a specific photoreceptor cell in the human retina, the melanopsin, responsible (during the phototransduction process) for synchronizing the biological clock in the human: throughthe use of higher or lower lighting levels, it is possible to inhibit the production of melatonin, inducing a higher concentration; in fact, melatonin levels increase during the night, when light is low, stimulating the sleep onset (McIntyre et al., 1989); on the contrary, over-lighting or close light flashes provoke dazzle, that by reducing the perceiver's visibility and visual performance, bring out discomfort, stress, sense of danger, and disorientation in the individual, that if sustained over time may lead to neuropsychiatric disorders: human is a photosensitive being (Bruce \& Green, 1990; Daurat et al., 1993).

\section{Conclusion}

By using the outcomes of these investigations, Light Design and Light Art might propose-from the point of view of human health — an integrated, strategic and "healthy" use of the light sources, in order to improve the psychophysiological wellness of the individual (healthy lighting), the holistic-perceptive experience relating to a specific architectural environment (e.g. the exhibition space in a museum or art gallery, but also the home interior, or the working space in an office), and, moreover, concerning the aesthetic appreciation of a space, object or artwork and their affordance: since the photobiological lighting effects are related to the characteristics of light energy incident on human retina, a different modulation of the light stimulus and its chromatic range has not only the role of making pleasant, comfortable or simply significant a given environment for a perceiver, but also improving the health and wellness of the individual, according to a specific ecological approach to visual perception (Gibson, 1979).

\section{References}

Arnheim, R. (1954). Art and Visual Perception: A Psychology of the Creative Eye. Berkeley-Los Angeles, CA: California University Press.

Badia, P., Myers, B., Boecker, M., \& Culpepper, J. (1991). Bright Light Effects on Body Temperature, Alertness. EEG and 
Behavior. Physiology \& Behavior, 50, 583-588. http://dx.doi.org/10.1016/0031-9384(91)90549-4

Berry, P. C. (1961). The Effect of Colored Illumination upon Perceived Temperature. Journal of Applied Psychology, 45, 248-250. http://dx.doi.org/10.1037/h0040221

Birren F. (1969a). Light, Colour and Environment: A Thorough Presentation of Facts on the Biological and Psychological Effects of Colour. New York: Van Nostrand Reinhold Co.

Birren, F. (1969b). Physiological Implication of Colour and Illumination. http://www.ies.org/PDF/100Papers/018.pdf

Boyce, P. (2003). Human Factors in Lighting. London/New York: Taylor \& Francis. http://dx.doi.org/10.1201/9780203426340

Boyce, P. R., Eklund, N. H., \& Simpson, S. N. (2000). Individual Lighting Control: Task Performance, Mood, and Illuminance. Journal of the Illuminating Engineering Society, 29, 131-142. http://dx.doi.org/10.1080/00994480.2000.10748488

Bruce, V., \& Green, P. R. (1990). Visual Perception: Physiology. Psychology and Ecology. Hove, UK: Lawrence Erlbaum Associates Ltd.

Burg, A. (1967). Light Sensitivity as Related to Age and Sex. Perceptual Motor Skills, 24, 1275-1288.

Butterfield, J. (1996). The Art of Light and Space. New York, NY: Abbeville Press.

Collins, B. (1993). Evaluation of Subjective Response to Lighting distributions: A Literature Review. NISTIR 519, Gaithersburg, MD: National Institute of Standards and Technology.

Daurat, A., Aguirre, A., Foret, J., Gonnet, P., Keromes, A., \& Benoit, O. (1993). Bright Light Affects Alertness and Performance Rhythms during a 24-h Constant Routine. Physiology and Behavior, 5, 929-936. http://dx.doi.org/10.1016/0031-9384(93)90271-G

Flynn, J. E. (1973). The Psychology of Light: Orientation as a Visual Task. Electrical Consultant, 1, 10-21.

Flynn, J. E. (1977). A Study of Subjective Responses to Low Energy and Nonuniform Lighting Systems. Lighting Design and Applications, 7, 6-15.

Flynn, J. E. (1988). Lighting Design Decisions as Interventions in Human Visual Space. In J. Nasar (Ed.), Environmental Aesthetics: Theories, Research and Application (pp. 156-169). New York: Cambridge University Press. http://dx.doi.org/10.1017/CBO9780511571213.018

Flynn, J. E., Hendrick, C., Spencer, T., \& Martyniuk, O. (1979). A Guide to Methodology Procedures for Measuring Subjective Impressions in Lighting. Journal of the Illuminating Engineering Society, 8, 95-110. http://dx.doi.org/10.1080/00994480.1979.10748577

Flynn, J. E., Spencer, T. J., Martyniuk, O., \& Hendrick, C. (1973). Interim Study of Procedures for Investigating the Effect of Light on Impression and Behavior. Journal of the Illuminating Engineering Society, 3, 87-94. http://dx.doi.org/10.1080/00994480.1973.10732231

Fusco, A. (2005). Analisipsicologica di alcuneopere di Anton Chekhov: Unastorianoiosa. In A. Fusco, \& R. Tomassoni (Eds.), Psicologia e comunicazioneletteraria (pp. 146-170). Milan: Franco Angeli.

Fusco, A. (2005). Analisipsicologica di alcuneopere di Anton Chekhov: L’uvaspina. In A. Fusco, \& R. Tomassoni (Eds.), Psicologia e comunicazioneletteraria (pp. 99-105). Milan: Franco Angeli.

Fusco, A. (2012). Dikter (pp. 48, 62, 80). Frosinone: Teseo Editore.

Fusco, A., Tomassoni, R., \& Grimaldi, D. (2011). Differenze e affinitàpsicologichetra Ibsen e Bracco e tra Bergman e Pirandello. In A. Fusco, \& R. Tomassoni (Eds.), Proceedings of the International Congress on "Similarities and Differences between Scandinavian and Italian Culture” (pp. 74). Frosinone: Teseo Editore.

Galetta, G. (2014). An Introduction to the Aesthetic Precognition: Threat or Opportunity for Contemporary Art? Universal Journal of Psychology, 2, 248-254.

Gibson, J. J. (1979). The Ecological Approach to Visual Perception. Boston, MA: Houghton Mifflin.

Ginthner, D. A. (2002). Lighting: Its Effect on People and Spaces. http://www.informedesign.org/_news/feb_v02-p.pdf

Kaplan, R., \& Kaplan, S. (1989). The Experience of Nature: A Psychological Perspective. New York: Cambridge University Press.

Kaplan, R., Kaplan, S., \& Ryan, R. L. (1998). With People in Mind: Design and Management of Everyday Nature. Washington DC: Island Press.

Kepes, G. (1944). Language of Vision. Chicago, IL: Paul Theobald \& Co.

Lam, W. M. C. (1992). Perception and Lighting as Formgivers for Architecture. New York: Van Nostrand Reinhold Co.

Mahnke, F., \& Mahnke, R. (1987). Color and Light in Man-Made Environments. New York: Van Nostrand Reinhold Co.

Martindale, C., Locher, P., \& Petrov, V. M. (Eds.) (2007). Evolutionary and Neurocognitive Approaches to Aesthetics, Crea- 
tivity, and the Arts. Amityville, NY: Baywood Publishing.

McIntyre, I. M., Norman, T. R., Burrows, G. D., \& Armstrong, S. M. (1989). Human Melatonin Suppression by Light Is Intensity Dependent. Journal of Pineal Research, 6, 149-156. http://dx.doi.org/10.1111/j.1600-079X.1989.tb00412.x

Sabra, A. I. (1981). Theories of Light: From Descartes to Newton. Cambridge: Cambridge University Press.

Solomon, P. et al. (Eds.) (1961). Sensory Deprivation. Cambridge, MA: Harvard University Press. http://dx.doi.org/10.4159/harvard.9780674864818

Tiller, D. K. (1990). Toward a Deeper Understanding of Psychological Aspects of Lighting. Journal of the Illumination Engineering Society, 19, 155-160. http://dx.doi.org/10.1080/00994480.1990.10747963

Tomassoni, R. (2014). Psychological Aspects in the Hyppolitus by Euripides. Quarterly Journal of the Association of Psychology and Psychiatry for Adults and Children, 21, 2-3.

Veitch, J. A., \& Newsham, G. R. (1998). Lighting Quality and Energy-Efficiency Effects on Task Performance, Mood, Health, Satisfaction and Comfort. Journal of the Illuminating Engineering Society, 27, 107-129. http://dx.doi.org/10.1080/00994480.1998.10748216

Wackermann, J., Pütz, P., \& Allefeld, C. (2008). Ganzfeld-Induced Hallucinatory Experience, Its Phenomenology and Cerebral Electrophysiology. Cortex, 44, 1376-1378. http://dx.doi.org/10.1016/j.cortex.2007.05.003

Zeki, S. (1999). Inner Vision: An Exploration of Art and the Brain. Oxford and New York: Oxford University Press.

Zeki, S. (2008). Con gli occhi del cervello: Immagini, luci, colori. Rome: Di Renzo Editore. 